\title{
Utjecaj promjena u porezu na dohodak na porezni teret građana
}

SLAVKO BEZEREDI Institut za javne financije

U želji da osigura veću pravednost u oporezivanju dohotka fizičkih osoba, Vlada RH je donijela novi, izmijenjeni Zakon o porezu na dohodak koji je stupio na snagu I. ožujka 20I2. ${ }^{1} \mathrm{No}$ vim izmjenama Vlada želi omogućiti porast neto dohotka za niže kategorije dohotka, te smanjiti neto dohodak za više kategorije dohotka. ${ }^{2}$ Povećanjem osobnog odbitka i promjenama poreznih razreda (tablica I) Vlada očekuje smanjenje prihoda općeg proračuna za oko 340 milijuna kuna na godišnjoj razini, čime bi se povećao raspoloživi dohodak stanovništva.

Nadalje, Vlada uvodi i novu kategoriju oporezivog dohotka, a to su dividende i udjeli u dobiti. Također, uvodi i oporezivanje dodatka na mirovinu koji postaje sastavni dio mirovine, te uvodi i oporezivanje mirovina iz inozemstva na isti način na koji se oporezuju i mirovine u tuzemstou. Time država planira povećati porezne prihode za oko 290 milijuna kuna.

\section{Tablica I.}

Promjena osobnog odbitka i poreznih razreda (u kn)

\begin{tabular}{|c|c|c|c|}
\hline & & Stari sustav & Novi sustav \\
\hline Osobni odbitak & & I.800 & 2.200 \\
\hline \multirow{3}{*}{$\begin{array}{l}\text { Oporezivi dohodak } \\
\text { po stopi (u \%) }\end{array}$} & $\mathrm{I} 2$ & $0-3.600$ & $0-2.200$ \\
\hline & 25 & 3.600-10.800 & $2.200-8.800$ \\
\hline & 40 & $>10.800$ & $>8.800$ \\
\hline
\end{tabular}

Izvor: NN 22/I2.
Promjenama zakona očekuje se smanjenje poreznih prihoda za oko 50 milijuna kuna. U slijedećim će se poglavljima analizirati hoće li navedene promjene ispuniti Vladina očekivanja, te tko su dobitnici a tko gubitnici u novom sustavu oporezivanja.

\section{ANALIZA POREZNOG TERETA}

U ovom dijelu analize koriste se hipotetički podaci o dohocima osoba iz skupina A i B. Pretpostavimo da zarađuju samo dohodak od plaće, te da osobe iz skupine A koriste samo osnovni osobni odbitak, a osobe iz skupine B uz osnovni koriste i dodatni osobni odbitak za dvoje uzdržavane djece. Iznos dodatnog osobnog odbitka za dvoje djece dobiva se množenjem osnovnog osobnog odbitka i faktora osobnog odbitka koji za dvoje djece iznosi I,2 (za prvo dijete o,5, a za drugo o,7), što prema starom poreznom sustavu (SS) iznosi 2.I6o, a prema novom (NS) 2.640 kuna. Obje skupine plaćaju prirez po stopi od I8\%. Izračunate su prosječne porezne stope (PPS) za osobe iz skupina A i B u starom i novom sustavu, te se uspoređuju dobiveni rezultati. PPS govori koliki je postotni omjer između poreza ${ }^{3}$ i dohotka. Iz grafikona I se vidi da PPS u oba slučaja raste s dohotkom, što znači da porez na dohodak relativno više opterećuje obveznike s višim dohocima, odnosno da je sustav oporezivanja progresivan. ${ }^{4}$
I Zakon o porezu na dohodak (NN I77/O4, 73/O8, 80/IO, II4/II, 22/I2).

2 Dohotkom se smatra dohodak nakon plaćenih doprinosa i prije plaćanja poreza na dohodak i prireza, a neto dohodak je dohodak koji ostaje nakon plaćanja poreza na dohodak i prireza.
3 U ovom radu će se porez na dohodak i prirez skraćeno zvati porez. 4 O progresivnosti poreza na dohodak u Hrvatskoj, vidjeti Urban (2006). 


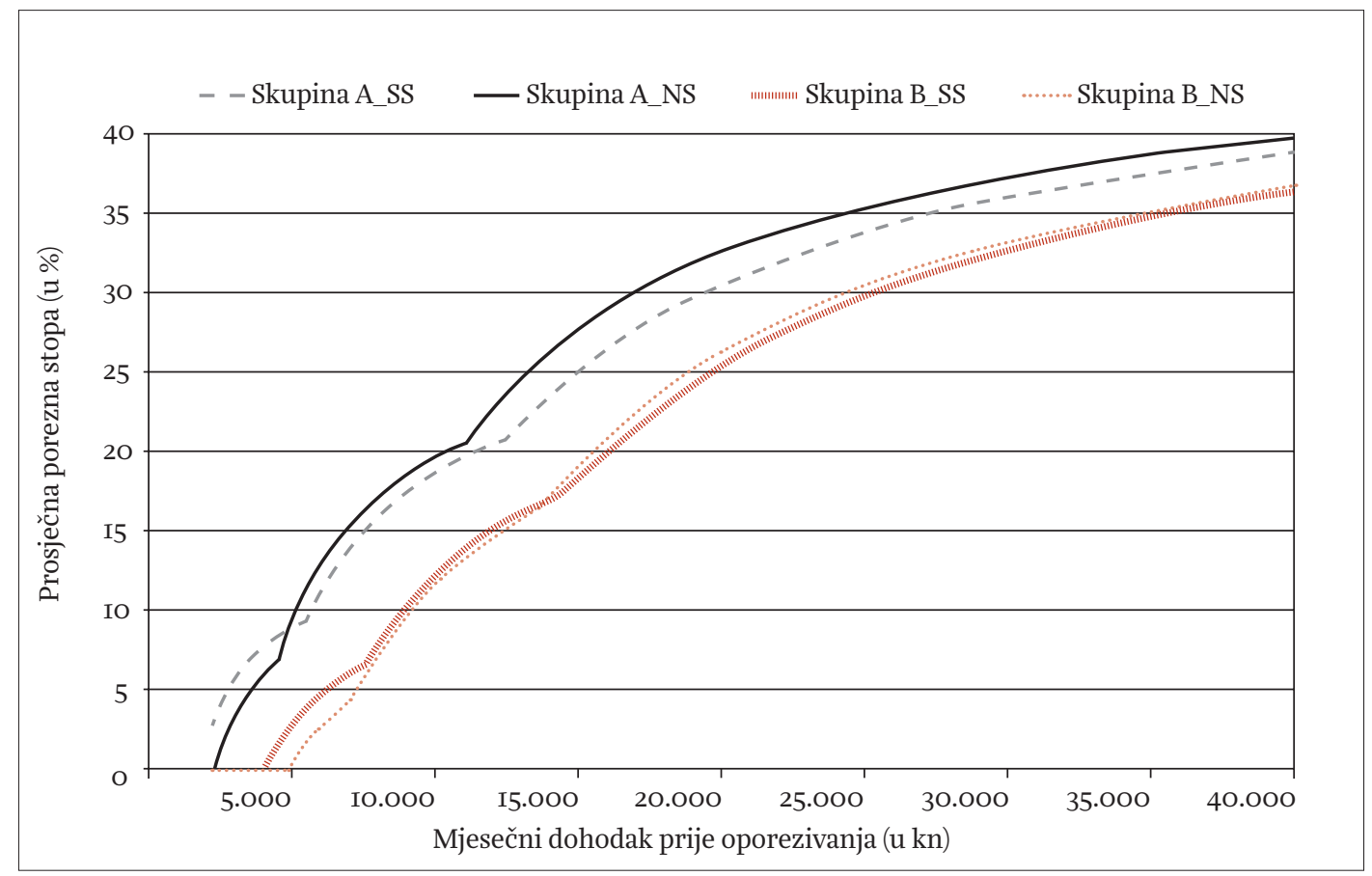

Izvor: izračun autora

Također, vidi se da je PPS za svaku razinu dohotka viši za osobe iz skupine A, jer osobe iz skupine B imaju veći osobni odbitak. Krivulje PPS-a prema starom i novom sustavu za skupinu A sijeku se kod dohotka od $4.800 \mathrm{kn}$. Na toj razini PPS iznosi 8,9\%, što znači da taj postotak dohotka odlazi državi. Za dohotke manje od $4.800 \mathrm{kn}$, PPS je u novom sustavu niži za oko 2 postotna boda. S druge strane, za dohotke veće od 4.800 kn PPS je u novom sustavu viši i to za oko 2 postotna boda za dohotke od 4.800 do I2.500 kuna. Najveće povećanje PPS-a - za oko 3 postotna boda - javlja se za dohotke između I2.500 i I5.0oo kuna. S rastom razine dohotka, razlika između PPS-a u starom i novom sustavu se postupno smanjuje i kod dohotka od $40.000 \mathrm{kn}$ iznosi o,95 postotna boda.

Za osobe iz skupine B, u novom sustavu PPS je niži za dohotke ispod I3.90o kn, dok se za dohotke iznad te granice PPS povisio. Najveće razlike u PPS-u između novog i starog sustava su kod nižih razina dohotka, gdje je za dohotke između 4.500 i $7.000 \mathrm{kn}$ PPS u novom sustavu manji za oko 2 postotna boda. Za veće dohotke se razlika u PPS-u smanjuje i postaje neznatna sve do dohotka od oko I3.90o kn kod kojeg se PPS u starom i novom sustavu izjednačava i iznosi 17,I\%. Za dohotke od I3.900 do 20.000 kn, PPS je u novom sustavu viši za oko I postotni bod, a daljnjim povećanjem dohotka ta se razlika smanjuje i kod dohotka od $40.000 \mathrm{kn}$ iznosi o,38 postotna boda.

Radi dobivanja stvarnije slike, grafikon 2 uspoređuje PPS za obitelji iz skupina C i D kroz stari i novi sustav. Obitelji iz skupine C se sastoje od dva odrasla zaposlena člana, a obitelji iz skupine D imaju dva odrasla zaposlena člana i dvoje uzdržavane djece. Pretpostavlja se da oba odrasla člana u svakoj obitelji rade i zarađuju jednake dohotke koji se zbrajaju i predstavljaju ukupan dohodak obitelji. Iz grafikona 2 se vidi da je PPS skupine C veći od PPS-a skupine $\mathrm{D}$ po starom i novom sustavu, jer jedan odrasli član u obiteljima iz skupine D ostvaruje pravo na dodatni osobni odbitak za dvoje djece; članovi obitelji iz skupine C ostvaruju samo osnovni osobni odbitak jer nemaju djece.

Usporedba PPS-a za skupinu C po starom i novom sustavu slična je usporedbi za skupinu A, jer se obitelji iz skupine C zapravo sastoje od dviju osoba iz skupine A. U ovoj skupini je za dohotke manje od 9.6oo kn PPS po novom sustavu niži za oko 2 postotna boda. Za dohotke veće od 9.6oo kn PPS je po novom sustavu viši i to za oko 2 postotna boda na intervalu između 9.600 i $24.500 \mathrm{kn}$, dok je na intervalu između 24.500 i 30.000 viši za oko 3 postotna boda. Daljnjim porastom dohotka postepeno se smanjuje razlika u PPS-u prema starom i novom sustavu.

Promatrajući dohodak obitelji iz skupine D, vidljivo je da se u novom sustavu PPS smanjio za oko I postotni bod za dohotke niže od Io.50o kuna, dok je na intervalu između I0.500 i 22.400 kn PPS približno jednak. Kod dohodaka viših od I4.40o kuna PPS izračunat po novom sustavu postaje viši od PPS-a po starom sustavu, a povećanje veće od jednog postotnog boda ostvaruje se kod dohodaka viših od oko 24.000 kuna. 


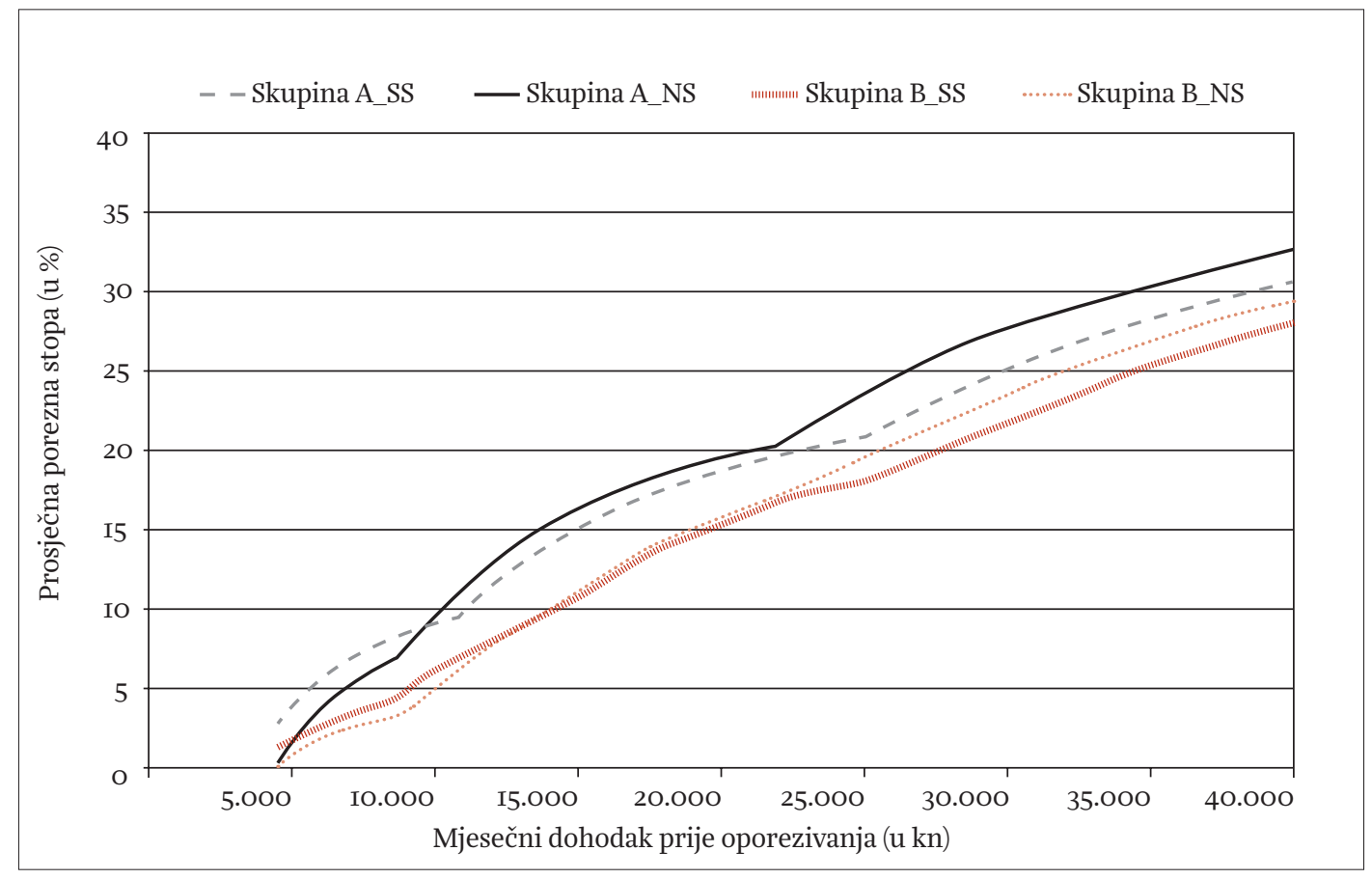

Izvor: izračun autora

\section{RASPODJELA POREZNOG OPTEREǴENJA}

U ovom dijelu se analizira raspodjela poreza prema starom i novom sustavu. Na temelju podataka iz Ankete o potrošnji kućanstava (APK) za 2008.5 se mikrosimulacijskim modelom izračunavaju i uspoređuju vrijednosti poreza prema starom sustavu koji je vrijedio 20II. i prema novom koji vrijedi od I. ožujka 2OI2. Kućanstva se sortiraju prema ukupnom mjesečnom dohotku po članu kućanstva, te se nakon toga svrstavaju u deset skupina s jednakim brojem pojedinaca (decilne skupine). ${ }^{6}$

Tablica 2 prikazuje prosječne vrijednosti različitih stavki po članu kućanstva. U prvom se stupcu prikazuju granice dohotka za svaku decilnu skupinu, u drugom prosjek ukupnih mjesečnih dohodaka, dok treći stupac iskazuje dio neoporezivog dohotka. U četvrtom i petom stupcu nalaze se prosječni iznosi poreza na dohodak izračunati mikrosimulacijskim modelom, prema starom i novom sustavu. U zadnjem stupcu se prikazuje koliku je promjenu porezne obveze donio novi sustav oporezivanja. Predznak plus predstavlja povećanje, a minus smanjenje porezne obveze.

Iz tablice 2 je vidljivo da se u novom sustavu smanjila porezna obveza za prvih osam decilnih skupina, koje pred-

5 Iz APK (koju provodi Državni zavod za statistiku) za 2008. dobivamo iznose dohodaka prije oporezivanja.

6 U APK su dani podaci na godišnjoj razini, međutim radi lakšeg razumijevanja godišnji podaci su pretvoreni na mjesečnu razinu, tako da je godišnji iznos podijeljen na I2 mjeseci. stavljaju 80\% stanovništva. U devetoj decilnoj skupini se porezna obveza tek neznatno povećala i to za 4 kune po članu kućanstva, dok deseta decilna skupina koja ujedno ima i najveća primanja, podnosi najveće povećanje porezne obveze od 86 kuna po članu kućanstva. Ukupni učinak je blago povećanje porezne obveze, što je u suprotnosti s pretpostavkom Vlade da će se porezni prihodi smanjiti, a takavjeusporednirezultatvjerojatnoposljedica korištenja različitih izvora podataka.

U tablici 3 se analiziraju udjeli pojedinih decilnih skupina $\mathrm{u}$ dohotku i porezu. Drugi stupac prikazuje koliki udio $\mathrm{u}$ ukupnom dohotku cjelokupnog stanovništva ima svaka decilna skupina.7 Treći i četvrti stupac prikazuju koliki je udio u ukupnom porezu platila svaka pojedina decilna skupina. Peti i šesti stupac prikazuju koliki je PPS za svaku decilnu skupinu. Iz drugog stupca se može primijetiti da četvrtina ukupnog dohotka stanovništva pripada desetoj decilnoj skupini, te da prvih pet decilnih skupina zaradi tek oko 28\% ukupnog dohotka. Promatrajući treći i četvrti stupac vidi se da najveći dio poreznog opterećenja snosi desetina stanovništva s najvećim primanjima. Za tu skupinu stanovništva dodatno se povećao udio u ukupnom porezu za 4,36 postotnih bodova, te sada plaća gotovo $62 \%$ ukupnog poreza. Nasuprot tome, donjih devet decilnih skupina zajedno plaćaju preostalih $38 \%$ od ukupnog pore-

7 Udio u ukupnom dohotku za svaku decilnu skupinu izračunava se po formuli: dohodak za pojedinu skupinu/ukupni dohodak cjelokupnog stanovništva $\times$ Ioo. 
Tablica 2.

Prosječni mjesečni iznosi dohotka i poreza po članu kućanstva (u kn)

\begin{tabular}{|c|c|c|c|c|c|c|}
\hline \multirow[t]{2}{*}{ Decilna skupina } & \multirow{2}{*}{$\begin{array}{c}\text { Dohodak } \\
\text { (granice razreda) }\end{array}$} & \multirow{2}{*}{$\begin{array}{c}\text { Prosjek } \\
\text { dohodaka }\end{array}$} & \multirow{2}{*}{$\begin{array}{l}\text { Neoporezivi } \\
\text { dio dohotka }\end{array}$} & \multicolumn{2}{|c|}{ Porez na dohodak } & \multirow{2}{*}{$\begin{array}{c}\text { Promjena } \\
\text { porezne obveze }\end{array}$} \\
\hline & & & & stari sustav & novi sustav & \\
\hline & $\mathbf{I}$ & 2 & 3 & 4 & 5 & $6=5-4$ \\
\hline I. & O-I.I37 & 831 & 303 & I & $\mathrm{O}$ & $-\mathrm{I}$ \\
\hline 2. & I.I37-I.5I5 & I.327 & 330 & 4 & 2 & -2 \\
\hline 3. & I.515-I.8I7 & I.672 & 360 & $\mathrm{I} 2$ & 6 & -6 \\
\hline 4. & I.8I7-2.097 & I.967 & 303 & 29 & 20 & -9 \\
\hline 5. & $2.097-2.376$ & 2.236 & 356 & 44 & $3 \mathrm{I}$ & $-\mathrm{I} 3$ \\
\hline 6. & $2.376-2.693$ & 2.534 & 306 & 68 & 52 & $-I 6$ \\
\hline 7. & $2.693-3.169$ & 2.912 & $4 \mathrm{I} 5$ & IO4 & 88 & $-\mathrm{I} 6$ \\
\hline 8. & $3.169-3.805$ & 3.473 & 402 & $\mathrm{I73}$ & I62 & $-\mathrm{II}$ \\
\hline 9. & $3.805-4.852$ & 4.268 & 404 & $3 \mathrm{I} 4$ & 3I8 & +4 \\
\hline IO. & $>4.852$ & 7.366 & 859 & I.006 & I.092 & +86 \\
\hline Ukupno & & 2.859 & 404 & I75 & I77 & +2 \\
\hline
\end{tabular}

Izvor: autorov izračun na temelju Ankete o potrošnji kućanstva iz 20o8. i uz pomoć mikrosimulacijskog modela

Tablica 3.

Udjeli dohotka i poreza po decilnim skupinama (u \%)

\begin{tabular}{|c|c|c|c|c|c|c|}
\hline \multirow[t]{3}{*}{ Decilna skupina } & \multirow{3}{*}{$\begin{array}{c}\text { Dohodak } \\
\text { (granice razreda, } \\
\text { u kn) }\end{array}$} & \multicolumn{3}{|c|}{ Udio u } & \multicolumn{2}{|c|}{ Prosječna porezna stopa } \\
\hline & & \multirow{2}{*}{$\begin{array}{c}\text { ukupnom } \\
\text { dohotku }\end{array}$} & \multicolumn{2}{|c|}{ ukupnom porezu } & \multirow[t]{2}{*}{ stari sustav } & \multirow[t]{2}{*}{ novi sustav } \\
\hline & & & stari sustav & novi sustav & & \\
\hline & $\mathbf{I}$ & 2 & 3 & 4 & 5 & 6 \\
\hline I. & O-I.I37 & 2,90 & O,04 & 0,02 & 0,08 & 0,04 \\
\hline 2. & I.I37-I.5I5 & 4,64 & $\mathrm{O}, 2 \mathrm{I}$ & 0,09 & 0,28 & O,II \\
\hline 3. & I.5I5-I.8I7 & 5,84 & 0,70 & 0,32 & 0,74 & 0,34 \\
\hline 4. & I.8I7-2.097 & 6,87 & I,66 & I,II & $\mathrm{I}, 48$ & $\mathrm{I}, \mathrm{OO}$ \\
\hline 5. & $2.097-2.376$ & 7,80 & $2,5 \mathrm{I}$ & $\mathrm{I}, 72$ & $\mathrm{I}, 97$ & $\mathrm{I}, 37$ \\
\hline 6. & $2.376-2.693$ & 8,89 & 3,86 & 2,95 & 2,67 & 2,06 \\
\hline 7. & 2.693-3.169 & IO,I6 & 5,89 & 4,92 & 3,57 & $3, \mathrm{OI}$ \\
\hline 8. & 3.169-3.805 & $\mathrm{I} 2, \mathrm{I} 5$ & 9,85 & 9,I5 & 4,98 & 4,67 \\
\hline 9. & $3.805-4.852$ & 14,89 & 17,82 & 17,90 & 7,36 & 7,46 \\
\hline IO. & $>4.852$ & 25,86 & 57,46 & 61,82 & 13,65 & 14,83 \\
\hline Ukupno & & IOO & IOO & IOO & 6,15 & 6,20 \\
\hline
\end{tabular}

Izvor: autorov izračun na temelju Ankete o potrošnji kućanstva iz 2008. i uz pomoć mikrosimulacijskog modela

\section{Tablica 4.}

Prosječni mjesečni iznosi dohotka i poreza po članu kućanstva za desetu decilnu skupinu (u kn)

\begin{tabular}{|c|c|c|c|c|c|c|}
\hline \multirow[t]{2}{*}{ Podskupina } & \multirow{2}{*}{$\begin{array}{c}\text { Dohodak } \\
\text { (granice razreda) }\end{array}$} & \multirow{2}{*}{$\begin{array}{c}\text { Prosjek } \\
\text { dohodaka }\end{array}$} & \multirow{2}{*}{$\begin{array}{l}\text { Neoporezivi } \\
\text { dio dohotka }\end{array}$} & \multicolumn{2}{|c|}{ Porez na dohodak } & \multirow{2}{*}{$\begin{array}{c}\text { Promjena } \\
\text { porezne obveze }\end{array}$} \\
\hline & & & & stari sustav & novi sustav & \\
\hline & $\mathbf{I}$ & 2 & 3 & 4 & 5 & $6=5-4$ \\
\hline IO.I. & $4.852-5.273$ & 5.083 & 492 & 479 & $5 \mathrm{OI}$ & +22 \\
\hline IO.2. & $5.273-5.878$ & 5.519 & 657 & 500 & 53I & $+3 \mathrm{I}$ \\
\hline IO.3. & $5.878-6.967$ & 6.344 & $67 \mathrm{I}$ & 695 & 758 & +63 \\
\hline IO.4. & $6.967-8.670$ & 7.660 & 809 & 973 & I.086 & $+\mathrm{II} 3$ \\
\hline IO.5. & $>8.760$ & I2.185 & I.663 & 2.372 & 2.574 & $+2 \mathrm{O} 2$ \\
\hline Skupina & $>4.852$ & 7.366 & 859 & I.006 & I.092 & +86 \\
\hline
\end{tabular}

Izvor: autorov izračun na temelju Ankete o potrošnji kućanstva iz 2008. i uz pomoć mikrosimulacijskog modela 
Tablica 5.

Udjeli dohotka i poreza za desetu decilnu skupinu (u \%)

\begin{tabular}{|c|c|c|c|c|c|c|}
\hline \multirow[t]{3}{*}{ Podskupina } & \multirow{3}{*}{$\begin{array}{c}\text { Dohodak } \\
\text { (granice razreda, } \\
\text { u kn) }\end{array}$} & \multicolumn{3}{|c|}{ Udio u } & \multicolumn{2}{|c|}{ Prosječna porezna stopa } \\
\hline & & \multirow{2}{*}{$\begin{array}{c}\text { ukupnom } \\
\text { dohotku }\end{array}$} & \multicolumn{2}{|c|}{ ukupnom porezu } & \multirow[t]{2}{*}{ stari sustav } & \multirow[t]{2}{*}{ novi sustav } \\
\hline & & & stari sustav & novi sustav & & \\
\hline & I & 2 & 3 & 4 & 5 & 6 \\
\hline IO.I. & $4.852-5.273$ & 3,6 & 5,5 & 5,7 & 9,4 & 9,9 \\
\hline IO.2. & $5.273-5.878$ & 3,9 & 5,7 & 6,0 & $9, \mathrm{I}$ & 9,6 \\
\hline IO.3. & $5.878-6.967$ & 4,4 & 7,9 & 8,6 & $\mathrm{II}, \mathrm{O}$ & $\mathrm{I} 2, \mathrm{O}$ \\
\hline I0.4. & $6.967-8.670$ & 5,4 & II, 2 & 12,4 & $\mathrm{I} 2,7$ & $\mathrm{I} 4,2$ \\
\hline IO.5. & $>8.760$ & 8,6 & 27,2 & 29,2 & 19,5 & $2 \mathrm{I}, \mathrm{I}$ \\
\hline Skupina & $>4.852$ & 25,9 & 57,5 & 61,8 & 13,7 & $\mathrm{I} 4,8$ \\
\hline
\end{tabular}

Izvor: autorov izračun na temelju Ankete o potrošnji kućanstva iz 2008. i uz pomoć mikrosimulacijskog modela

za. Za svih prvih osam decilnih skupina, udio u ukupnom porezu smanjio se za manje od I postotni bod, dok se za devetu skupinu povećao za o,o8 postotnih bodova. Prema tome, najveće su se promjene dogodile za desetinu stanovništva s najvećim primanjima.

Zbog „otvorenosti” desete decilne skupine ${ }^{8}$ detaljnije će se prikazati rezultati za desetinu stanovništva s najvećim dohotkom. Kućanstva iz desete decilne skupine dodatno su podijeljena u pet podskupina prema rastućem ukupnom mjesečnom dohotku po članu kućanstva. Promatrajući promjene porezne obveze u tablici 4 vidi se kako se promijenila porezna obveza u svakoj podskupini. Za svaku od prve tri podskupine je povećanje porezne obveze manje od ukupnog povećanja za cijelu skupinu koje iznosi $86 \mathrm{kn}$, dok se za dohotke veće od $8.760 \mathrm{kn}$ porezna obveza povećala za $202 \mathrm{kn}$.

Tablica 5 pokazuje da se u drugoj podskupini dogodio mali pad PPS-a, zbog toga što razlika u neoporezivom dohotku po članu kućanstva u odnosu na prethodnu podskupinu iznosi I65 kn i što se radi o manjem broju podataka. U svakoj idućoj skupini PPS se povećava u odnosu na prethodnu i u petoj podskupini iznosi 2I,I\% što je povećanje za I,6 postotnih bodova u odnosu na stari sustav. Peta podskupina, koju čine $2 \%$ ljudi s najvišim dohotkom, zaradila je 8,6\% ukupnog dohotka stanovništva, ali plaća više od četvrtine iznosa ukupnog poreza u starom $(27,2 \%)$ i no$\operatorname{vom}(29,2 \%)$ sustavu.

8 Za desetu decilnu skupinu se kaže da je „otvorena” zbog toga što se u njoj nalaze svi dohoci veći od $4.852 \mathrm{kn}$. Drugim riječima, u njoj su najveće razlike između dohodaka po pojedinim članovima kućanstva jer nije poznat najveći dohodak.

\section{ZAKLJUČAK}

Je li novi sustav oporezivanja pravedniji od staroga? Ovisi o tome promatraju li se promjene sa stanovišta ljudi s manjim ili većim dohocima. Desetini stanovništva $\mathrm{s}$ najvećim primanjima po članu kućanstva svakako nije, jer je ta populacija i do sada plaćala više poreza nego svi ostali zajedno. Iz zadnjeg stupca u tablici 3 vidi se da gotovo I5\% posto njihova dohotka odlazi na plaćanje poreza, što je povećanje za I,I7 postotnih bodova u odnosu na stari sustav. Međutim, učinak dodatnog poreznog opterećenja za građane s najvišim dohocima bio je očekivan, budući da je novi zakon donesen s ciljem povećanja neto dohodaka za građane s nižim dohocima i smanjenja neto dohodaka građana s višim dohocima. Tablica 2 pokazuje da za $20 \%$ stanovnika s najnižim dohocima novi sustav nije donio osobito povećanje neto dohotka, jer su zbog malih prihoda i prije plaćali mali porez. Budući da imaju najveće smanjenje porezne obveze za I6 kuna po članu kućanstva, može se reći da su novim sustavom najviše dobili građani koji pripadaju šestoj i sedmoj decilnoj skupini (dohodak od 2.376 do $3.169 \mathrm{kn}$ ). Novi sustav oporezivanja očito neće dovesti do povećanja prihoda najsiromašnijih skupina stanovništva, te bi im država mogla više pomoći socijalnim davanjima i doplatkom za djecu.

\section{LITERATURA}

Ministarstvo financija RH, 2012. Prijedlog zakona $o$ izmjenama i dopunama zakona o porezu na dohodak $s$ konačnim prijedlogom zakona. Zagreb: Ministarstvo financija.

Urban, I., 2006. „Što porez na dohodak u Hrvatskoj čini progresivnim?” Newsletter, br. 23. Zagreb: Institut za javne financije. 